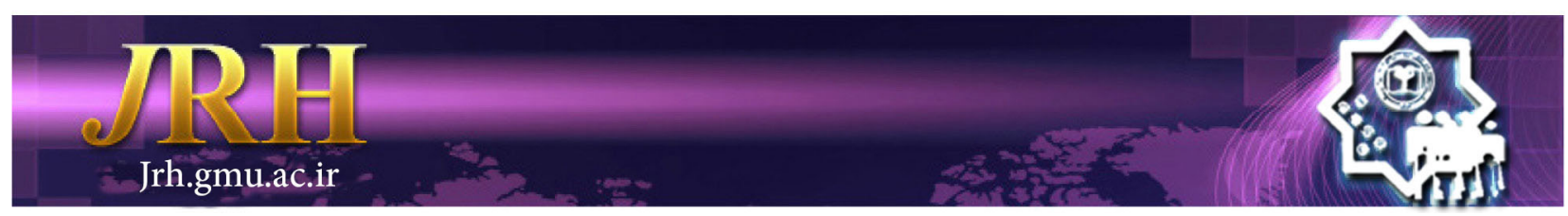

\title{
Effect of an intervention based on socio-ecological model in promoting physical activity of female employees \\ Amineh Sahranavard Gargari ${ }^{1}$, Fatemeh Sadat Hosseini² ${ }^{2}$, Malek
} Ahmadi $^{3}$

\author{
Journal of Research \& Health \\ Social Development \& Health Promotion \\ Research Center \\ Vol. 8, No. 2, Mar \& Apr 2018 \\ Pages: 163- 172 \\ DOI: $10.29252 / j$ irh.8.2.163 \\ Original Article
}

1. Correspondence to: Department of Motor Behavior, Faculty of Physical Education and Sport Sciences Urmia University, Urmia, Iran Email: amineh sahranavard@yahoo.com

2. Department of Motor Behavior, Faculty of Sport Sciences, Urmia University, Urmia, Iran

3. Department of Motor Behaviour, Young Researchers and Elite Club, Urmia Branch, Islamic Azad University, Urmia, Iran

\section{Received: 23 May 2016}

Accepted: 21 Nov 2016

How to cite this article: Sahranavard Gargari A, Hosseini FS, Ahmadi M. Study on the effectiveness of an intervention based on socio-ecological model in promoting physical activity of female employees of all universities of Shabestar. J Research \& Health2018; 8(2): 163- 172.

\begin{abstract}
Although active life style is one of the main determining factors of health, the level of regular physical activities in women is less than in men and even this level decreases with aging. The aim of this study was to determine the effect of an intervention based on the social ecological model on promotion of physical activity among female employees. In this study, 160 women employed at Shabestar universities were selected, and randomly divided into two groups of control $(n=80)$ and intervention $(n=80)$. The intervention group received an instructional program according to the model, including one session for general instruction and four sessions for group discussion along with daily walking for 30 minutes within 8 weeks. In order to objectively measure the physical activity, the pedometer was used and to measure the perceived physical activity, the long form of International Physical Activity Questionnaire (IPAQ) was applied. The variables related to the components of socio-ecological model were measured using the socio-ecological model questionnaire. A significant difference was found between two groups after the intervention in terms of That is, the average number of steps in walking in the intervention group increased significantly (from 4204 to 7882 steps per day), while it did not significantly increase in the control group. Thus, it can be argued that designing and implementing the interventional programs based on the socioecological model can promote physical activity behavior among employed women.
\end{abstract}

Keywords: Employees, Female, Physical Activity

\section{Introduction}

The lack of enough agility and physical activity in life is one of the most important disabling factors responsible for $22 \%$ of cardiovascular disease, $22 \%$ of intestinal cancer, $18 \%$ of osteoporosis, $12 \%$ of hypertension and diabetes, and $5 \%$ of breast cancer cases in the United States of America [1]. Spread of technology and mechanical life has led to the reduction of human physical activity; while,
$70 \%$ of the diseases occur as a result of the lack of movement [2]. Immobile life style is an important factor leading to the death, disease, failure, or disability in the individuals. Regular physical activity is a necessity for human health and immobility is a global problem against improving the public health, one of ten effective factors in mortality and disability in the community [3]. 
Physical activity has an important role in family communication and different social activities. As an outcome of the health, physical activity also has a significant effect in creating healthy living, safety, and mental and social welfare for the people and societies. The establishment of a healthy and happy society needs the effort of healthy, efficient, and intellectual labor forces [4]. Due to importance of the regular physical activity in creating and maintaining the health, this behavior has been listed as one of the 15 priorities to change the health recovery behavior. Furthermore, scientific observations have shown that the physical activity can be very influential in health in all ages [2-4]. According to results of 27 meta-analysis conducted by the world health organization, regular physical activity can be very effective in reducing 35$55 \%$ of cardiac infarction cases and it can also decrease the rate of mortality. The American sports medicine college in 2014 recommended physical activities for three to five times a week. A similar duration has also been suggested by the world health organization [5]. New Zealand's ministry of health has categorized the physical activity based on its intensity in three levels of light, moderate, and intense [6].

The physical activity is a multi-factorial behavior affected by the interpersonal, environmental, and social factors [4-9]. Social, physical, and political environments affect people's ability to participate in physical activities. For increasing physical activities, effort not only should be conducted on behavioral selection of individuals but on the factor that affect the choice [10]. Recent evidence shows the relationship between environmental and social factors and increased physical activities $[7,10,11]$. Due to limitations of socialpsychological models, the use of the ecologicalsocial model seems more evident [12]. In the studies, which have used social-psychological models, and in descriptive studies, which have applied socio-ecological models, the emphasis has been on a second model in the interventions for improving physical activities. Thus, as a proper model which includes multilevel changes at personal level, social, physical, and political environments, the socio-ecological model of health improvement of Stokol has identified the core hypothesis of this model that has been also confirmed by Glanz. This model components are individual factors and surrounding social, physical, and political environments. in this model, the emphasis rests on the implication that the individual is not separated from his/her environment but the social-physical environment affects the person's behavior and physical activities [9]. The personal factors that affect the increase or decrease of physical activity include the knowledge, attitude, perceived barriers and benefits, self-efficacy, cues to action and motivation, sport-specific skills and motor skills, disability and injuries, age, gender, literacy, socio-economic status, employment status, and personal strategies, including focus on changing personal awareness, attitude, behaviors, and skills [7,12,13]. Social environment surrounds the person in the socio-ecological modeland includes the communications, culture, and community through which the person is in relation to others and hence it has a significant influence on physical activity. For example, being in association with person, family, or coworkers who have physical activity can influence physical activity behavior of a person [13-17]. The physical environment can influence the degree and type of the physical activity, positively or negatively. Bike paths, sidewalks, access to parks, sports facilities, swimming pools, and sports clubs that are designed for physical activity,can have a positive impact on the level of activity, while other locations such as workplace, schools, houses and theaters can limit or prevent the physical activity [13,18-20].

Politics: regulations and policies are effective in physical activity although their effect is not visible. The policies are legislations enacted by the state or government and a series of informal local regulations set by schools or workplaces where it seems difficult to implement the strategies of promoting the physical activity $[13,14]$. The strengths of this 
model around the physical activity behavior can help recognize the related opportunities for optimizing the participation in the physical activity and also recognizing the multiple factors in behavior. Any effort to change the behavior will be successful when the multiple levels of influence are determined simultaneously. Today, women are responsible for several tasks within and outside the home. They play different roles in the family and society which put pressure on them. Under these circumstances, it would be difficult for them to devote time to perform physical activities [21]. The carried-out studies have also shown that women engage less in physical activity than men [11-22]. The world health organization has reported that $76.3 \%$ of 15-64-year-old Iranian women suffer from the immobility [7]. Cooli et al., estimated the rate of sport participation among people aged 20 to 79 in Canada. Results represented the fact that about $15 \%$ of adults in Canada had $150 \mathrm{~min}$ physical activity (moderate to intense) and $5 \%$ had 30min physical activity (moderate to intense) per week. Men were a little more active than women; the immobility time for men was $68 \%$ and this was $69 \%$ for women. Total times of immobility were about $575 \mathrm{~min} /$ day for men and $585 \mathrm{~min} /$ day for women [23]. Flori and Lee in a study on the physical activity of Afro-American women showed that the family social support and friends are the main motivational factors for achieving regular physical activity. They had performed physical activity in their leisure time at least $150 \mathrm{~min} /$ week in comparison with those who had received lower levels of support. Having a sport partner was also reported as one of the most crucial factors in increasing the level of physical activities among the studied group [24]. In a study conducted by Young and Stewart, it was shown that the support provided by family and friends made a significance influence on the physical activity and the social support predicted the variations of daily energy consumption significantly [25]. Coker et al., aimed to enhance the physical activity to reach to 10000 walks daily. They used the social ecological model and placed 79 people in the control group and 68 people in the intervention group; the physical environment intervention was the use of the stair instead of elevator for increasing the number of walks. The results showed that the number of the walks increased after the intervention among the intervention group individuals. In other activities based on the questionnaire, there was not observed a significant difference [26]. Ishi et al., investigated the influence of the personal, physical, and social environment factors based on the social-ecological model framework using the structural equation among Japanese people ranging from 20-79 years. The results showed that the physical environment had only indirect influence on the physical activity through the social and mental factors but the personal and social factors affected the physical activity, directly and indirectly. This study claimed that the intervention strategies must be used to optimize the physical activity [27]. Bakhtari et al., through investigating the effective factors on the physical activity of women working at Tabriz University showed that the personal factors had direct influence and the social had both direct and indirect (through individual factors) influence on the physical activity. They found a direct relationship between social support and the level of the physical activity. Eighty percent of the participants had light physical activity, $50 \%$ had moderate physical activity, and $32 \%$ had intense physical activity. Women employing in occupations such as offices and office-based affairs as well as boring jobs did not have enough physical activities; therefore, the mental and spiritual affairs should be also allocated in this pavement [3]. Regarding the importance of physical activity, perception of factors which encourage people to participate in this activity is important to promote populationbased physical activity. Furthermore, the need to recognize population-based strategies for improving physical activities through intervention seems obvious. Moreover, a continuous need for improving motivations for doing physical activities and experiencing new interventions is observed. Due to special cultural context, advances in technology, and 
changes in work patterns, which have affected the behavior of individuals at worksite, at home, and in community, the level of physical activity has reduced in Iran [3].

Since the role of physical activities has been proven in preventing diseases like cardiovascular diseases, reducing stress and anxiety, and increasing self-confidence and cooperation spirit, interventions based on social-ecological model help identifying effective factors in physical activities behaviors, and explaining human and environment's interaction by analyzing the levels and effective factors in these behaviors. Since no study has explored the physical activities using this model in Iran, conducting a study by applying this model seems necessary. All factors explained in previous statements provide the rationale for this study to determine the effect of an educational intervention period based on a social-ecological model on improving physical activities of employed women to encourage their participation in physical activities more than before and improve their mental-physical health.

\section{Method}

This interventional research was a type of quasi-experimental study with two groups (experimental and control groups). All women working at Shabestar universities in 2015 who did not show any chronic diseases and were not pregnant were included in this study. The ethical considerations were as follow: Explaining objective of the research, describing intervention procedure, and participants were assured of confidentiality and informed consent in written format was acquired form each them. The purpose of the present study was to investigate the effectiveness of an interventional period based on the social-ecological model on the level of physical activity. The sampling was carried out in two stages. In the first stage, random cluster sampling was applied. Sampling was continued using non-probability method of convenience sampling in the second stage. Out of 277 employed women, 160 were randomly selected and assigned into two groups of 80 (experimental and control groups). At the end of the study, the number of participants decreased to 76 in the experimental group and 73 in the control group. The educational program included one general and four group discussion $50 \mathrm{~min}$. The aim was to justify the participants about the trend of training program, how to use the pedometer, how to record the number of steps and report them, the benefits of walking 10000 steps per day, and how to walk properly. The first session of the educational program was devoted to attract the attention of the participants towards the program through making them conscious about the perceived benefits of the physical activity, risks arose from the lack of sufficient physical activity, and consequences of adopting the immobile lifestyle. In the second session, the emphasis was on the self-efficacy for fulfilling physical activity in which employees were discussed about their ensured ability to perform physical activities under different conditions such as responsibilities, lack of time, having guest, going travel and holiday, family problems as well as mental and spiritual disorders. The third session was held with emphasis on social support. The most important objective of the session was to change the attitudes of employees towards doing the physical activity, increasing their awareness about the importance of the coworkers, family and friends' role in promoting the physical activity through support and encouraging each other to do activities. In the fourth session, the obstacles and the strengths of the physical environment of universities dedicated to physical activities were discussed. Data gathering tool included a questionnaire on the demographic information (age, height, weight, number of children, education, employment status, marital status, disease background, spouse's job and level of education, and regular participation in physical activity sessions) and the social-ecological model questionnaire. This instrument comprised the perceived selfefficacy of the physical activity that included 18 questions developed by Bendora and assessed on a 4-point Likert scale [28]. The perceived benefits and barriers, including the 43-item questionnaire of Suchert on a 
4-point Likert scale is applicable for measuring the degree of the agreement and disagreement of respondent in which the individual's beliefs about barriers and benefits of physical activity are listed [29]. Social environment questionnaire developed by Sallis and colleagues was applied in order to measure the perceived social support related to the physical activity [30] in which 5 items measure the support provided by friends and coworkers during the past 3 months using a 5-point Likert scale (never to always). To assess the physical environment, Mojahed and colleagues' 8-item questionnaire in 2010 having subscales of availability to facilities, and environmental security and beauty was applied using a 5-point Likert scale [3]. The International Physical Activity Questionnaire (IPAQ) includes 27 items in 4 subscales to measure the physical activity under 4 various situations: at workplace, during leisure times, during commute, and at home. The degree of the total physical activity is measured based on metabolic index unit called as metabolic equivalent of task (MET). The degree of one MET is equal to the degree of the energy consumption when a person is at resting. In this study, numbers obtained from the people's metabolic equivalent put them in three categories of light, moderate, and intense in terms of being physically active; light (metabolic equivalent less than 600 MET-min/week), moderate (a combination of all walking activities, moderate and intense which totally being at least 600 MET$\mathrm{min} /$ week), and intense (a combination of all walking activities, moderate and intense so that the total should be at least $3000 \mathrm{MET}$-min/week). For objective measurement of physical activity, the pedometer of Omron model made in Japan was used in this study. The related instrument is a simple electronic device by $2 * 2$ inches size. This can be put into belt or pocket showing the step count and distance walked in mile or kilometer. Researchers have shown that pedometer is a reliable and valid instrument [3,7]. Based on the data obtained by a pedometer, participantc are classified into three categorize based on the number of steps per day: people walking little than 7499 walks a day are considered as immobile ones, while those having 7500-9999 walks a day are moderately active and those who take more than 10000 walks a day are active people [38]. The reliability of the instruments was examined by conducting a pilot study on 25 employed women using Cronbach's alpha test. Accordingly, the reliability coefficients were achieved as $0.69,0.9,0.9,0.84,0.76$, and 0.82 for perceived self-efficacy, perceived benefits, perceived barriers, social support, physical environment, and physical activity questionnaire, respectively. To analyze the data, the descriptive statistics (mean and standard deviation) and for confirming the hypotheses, the ANCOVA and Mann-Whitney U test were used. Data were analysed using SPSS software version 23. The significance level was set at $\mathrm{p}<0.05$.

\section{Results}

The mean age of participants was 42.07 (5.44 SD) years ranging from 25 to 53. In terms of matial status, $93.3 \%$ of them were married. Concerning education, $2.6 \%$ of women had Diploma, 30\% AD, 61.7\% BA, and 5.7\% MA, 93.5\% had formal employment and $6.5 \%$ had informal occupations. ANCOVA was used to investigate the effect of the intervention protocol on the constructs of the social-ecological model. With respect to the scores obtained in the pre-test and post-test in two groups, the following results were found.

Table 1 Results of ANCOVA on the scores of different constructs

\begin{tabular}{lccccccc}
\hline Constructs & $\begin{array}{c}\text { Total } \\
\text { squares }\end{array}$ & df & $\begin{array}{c}\text { Mean } \\
\text { squared }\end{array}$ & F & Sig & $\begin{array}{c}\text { Size of } \\
\text { effect }\end{array}$ & $\begin{array}{c}\text { Statistical } \\
\text { power }\end{array}$ \\
\hline Social support & 1537.05 & 1 & 1537.05 & 132.84 & 0.001 & 0.47 & 1 \\
Self-efficacy & 682.80 & 1 & 682.80 & 16.04 & 0.001 & 0.09 & 0.97 \\
Physical environment & 3072.34 & 1 & 3072.34 & 96.26 & 0.001 & 0.39 & 0.99 \\
Perceived benefits & 910.38 & 1 & 910.38 & 22.09 & 0.001 & 0.13 & 1 \\
Perceived barriers & 271.71 & 1 & 271.71 & 20.91 & 0.001 & 0.12 & 0.99 \\
\hline
\end{tabular}


With respect to F-values presented in Table 1, all components of socio-ecological model examined in this study significant $(p<0.05)$ implying a significant difference between two groups regarding studied constructs, including social support (F 132.84), self-efficacy (F 16.4), physical environment ( $\mathrm{F}$ 96.26), perceived benefits (F 22.09), and perceived barriers ( $F$ 20.91).

According to Table 2, the mean scores of constructs of social ecological model are higher in the intervention group than the control group, and with respect to the $\mathrm{F}$ test results, all these changes are significant. It can be claimed that the performed intervention based on social ecological model increase the social- ecological components. Descriptive statistics related to the level of physical activity of participants are shown in Table 3.

\begin{tabular}{|c|c|c|c|}
\hline Constructs & Group & Mean & Std error \\
\hline \multirow{2}{*}{ Social support } & Control & 0.13 & 0.38 \\
\hline & Experimental & 6.31 & 0.37 \\
\hline \multirow{2}{*}{ Self-efficacy } & Control & -0.15 & 0.76 \\
\hline & Experimental & 4.13 & 0.75 \\
\hline \multirow{2}{*}{$\begin{array}{l}\text { Physical } \\
\text { environment }\end{array}$} & Control & -0.45 & 0.66 \\
\hline & Experimental & 8.63 & 0.65 \\
\hline \multirow{2}{*}{$\begin{array}{l}\text { Perceived } \\
\text { benefits }\end{array}$} & Control & 0.06 & 0.75 \\
\hline & Experimental & 5.01 & 0.74 \\
\hline \multirow{2}{*}{$\begin{array}{l}\text { Perceived } \\
\text { barriers }\end{array}$} & Control & -2.23 & 0.42 \\
\hline & Experimental & -4.93 & 0.41 \\
\hline
\end{tabular}

\begin{tabular}{|c|c|c|c|}
\hline \multicolumn{2}{|c|}{ Level of physical activity } & $\begin{array}{c}\text { Pretest } \\
\mathrm{N}(\%)\end{array}$ & $\begin{array}{c}\text { Posttest } \\
\mathrm{N}(\%)\end{array}$ \\
\hline \multirow{3}{*}{ Control } & Light & $9(11.02)$ & $1(0.013)$ \\
\hline & Moderate & $25(65)$ & $53(71.6)$ \\
\hline & Intense & $(19(24.75)$ & $20(27.02)$ \\
\hline \multirow{3}{*}{ Intervention } & Light & $10(12.2)$ & 0 \\
\hline & Moderate & $46(57.4)$ & $39(51.8)$ \\
\hline & Intense & $24(30.4)$ & $37(48.2)$ \\
\hline
\end{tabular}

According to Table 4, the statistics $\mathrm{F}$ of the objective physical activity in the post-test was 5987.04, showing that there is a significant difference between both groups. The mean of the objective physical activity in the intervention group (55200.87), was higher than that of the control group (29624.26). Moreover, according to Table 4, the effect size showed that the participation in the interventional program based on the social-ecological model can justify about $97 \%$ of changes observed in the objective physical activity. The power of the test was calculated as 1 which is higher than 0.70 , representing the sufficiency of the sample size.

Table 4 ANCOVA results for difference between both studied groups in terms of objective physical activity

\begin{tabular}{lclcccc}
\hline Total squares & DF & Mean squared & F & Sig. & $\begin{array}{c}\text { Size of } \\
\text { effect }\end{array}$ & $\begin{array}{c}\text { Statistical } \\
\text { power }\end{array}$ \\
\hline $\begin{array}{l}24031487611.2 \\
586031128.8\end{array}$ & 1 & 24031487611.2 & 5987.04 & 0.001 & 0.97 & 1 \\
\hline
\end{tabular}


Table 5 Results of mann-whitney U test to determine the difference between two groups in terms of the level of subjective physical activity

\begin{tabular}{lcccc}
\hline & $\begin{array}{c}\text { Light physical } \\
\text { activity }\end{array}$ & $\begin{array}{c}\text { Moderate } \\
\text { physical activity }\end{array}$ & $\begin{array}{c}\text { Intense physical } \\
\text { activity }\end{array}$ & $\begin{array}{c}\text { Total physical } \\
\text { activity }\end{array}$ \\
\hline Mann & 644.50 & 769.00 & 1966.00 & 842.00 \\
Whitney U & 3345.50 & 3470.00 & 4667.00 & 3543.00 \\
Wilcoxson & -8.68 & -8.17 & -3.09 & -7.71 \\
Statistics Z & 0.001 & 0.001 & 0.002 & 0.001 \\
Sig level & & & & \\
\hline
\end{tabular}

The results of Mann-Whitney U test to investigate the difference between both groups regarding subjective physical activity indicated that the light physical activity (644.50) with statistics Z(-8.68), moderate physical activity (769.00) with statistics Z(-8.17), intense physical activity (1966.00) with statistics Z(-3.09), and total physical activity (842.0) with statistics Z(-7.71) all are significant at 0.01 level. Thus, the research hypothesis about the effect of intervention based on the social-ecological model on the level of the subjective physical activity of employed women is approved.

\section{Discussion}

The present study was a interventional study aimed to investigate the effect of a socialecological model based educational program on the level of physical activity among employedwomen at Shaebstar universities. Although the average number of steps at the beginning of the study was very low in both groups, even less than the recommended 10000 steps, the average number of steps in the intervention group increased significantly (4420 steps per day at the beginning versus 7882 at the end of the study). The participants' mean number of steps in the current investigation was lower than the mean number of steps reported in aonther study on Iranian men $(9339 \pm 607)$ [34]. A dramatic difference was observed between the findings of this study and those of other studies conducted in different countries concerning the average number of steps; for example, 8832 steps/day in Australia, 9007 steps/day in the UK [35], and 9584 steps/ day in Spain [3] . this difference can be due to differences in tasks and conditions [36], duration of the study, and cultural status of the participants[26].
In several studies, the mean for number of steps in people known as immobile at the beginning of the study was 7499 steps a day, which improved significantly after the intervention; this report is consistent with results of the present study [19,26,37]. Previous studies have shown that the rate of daily steps in employees increased after the intervention, just like the present study $[27,37,38]$. However, the findings of the current research are inconsistent with those of a study conducted at Catalan University [39]. This inconsistency may be related to the content of the intervention program, and tasks and conditions of the participants. Moreover, the authors of the latter study admitted that the awareness of Catalan University employees who participated in the study was at a low level regarding to the benefits of walking process; hence, the use of pedometer in the time of walking was considered as a very effective intervention for helping women increase their physical activity [40].

The results of the present study showed no significant difference between groups regarding the level of the subjective physical activity but after the intervention, a significant difference was observed. Due to differences in the mean of steps, it is specified that the level of the physical activity in the intervention group (7632) increased significantly in comparison with the non-intervention group (3543). In the present study, the level of light and moderate physical activities decreased in the intervention group from $12.2 \%$ to $0 \%$ and from $57.4 \%$ to $51.8 \%$, respectively, while it increased from $30.4 \%$ to $48.2 \%$ in the intense physical activity. Bakhtari et al., conducted a study in Iran and showed that about $18 \%$ of the participants had light physical activity, 
$50 \%$ moderate, and $32 \%$ intense, which are in line with the results of the present study [3]. Women are often employed in jobs which do not require much mobility, such as office works, office affairs, and jobs that are boring in terms of spiritual environment [12]. According to Mark Veden, the rate of inactivity in women in different parts of the world varies from $3 \%$ to $36 \%$. The difference can be originated from the target group of the study and type of variables; for example, the type of job and the age range of participants. Different studies have shown that the increase of women age can negatively affect their physical activities; of course, the lifestyle and industrialization of communities can also influence the level of physical activities in women [18].

The results of the present study also showed that the mean of scores of the social-ecological model components significantly related to the behavior in the intervention group by giving the values of social support as 132.84 , self-efficacy as 16.04 , physical environment as 96.26 , perceived benefits as 22.09, and perceived obstacles as 20.91 that all are significant at 0.01 level. This finding is in agreement with the results of Jalilian et al.'s study. According to previous literature, friends and family support along with the access to a proper physical environment have a significant relationship with the physical activity, which is in accordance with the present study results $[10,35]$. However, there is a contradiction between the results of this study and those of Solhi's study carried out on students to promote their physical activity, which may be due to age difference [36]. The findings of the present study is consistent with the results of the study carried out on the Afro-American women showing that the perceived social support is little among these women in comparison with women having higher rates of physical activity. Ishi et al., investigated the effect of the personal, physical environment, and social factors based on the social-ecological model framework using the structural equations among Japanese ranging from 20-79 years old and they showed that the physical environment is only indirectly influencing on the physical activity through the mental and social factors but the personal and social environment factors have both direct and indirect influence on the physical activities. Findings of review studies are consistent with the results of the present study for example? One limitation of this research related to the social-ecological model used in this study. Although this model has combined different levels of health promotion and created multidimensional effects, it leads to some problems or misunderstanding toward explanation and interpretation of health issues. Thus, the complexity of this model has limited its application in developing interventions. Moreover, this cross-sectional study was conducted on a sample at the age range of 25-35 with high education levels. Therefore, generalizing its results to women at other ages and education levels or housewives should be done with caution.

\section{Conclusion}

In general, the results suggested that intervention planning via the social ecological model can be effective in promoting physical activity among the female employees of universities. Since the emphasis of this model is not only on changing the individual factors, but on changing the physical and social environments, we can observe the promotion of the health-related behaviors because of the synergistic effect of the simultaneous changes on them. According to the results, people in the intervention group promoted the light level of physical activities to the moderate and intense levels after the intervention. Thus, employed educational program with the help of low-cost practices such as walking for 30 min a day at workplace was successful to improve the level of physical activity in individuals participated in this study.

\section{Acknowledgments}

This article was derived from a Ph.D dissertation by Amineh Sahranavard. I would like to appreciate the Vice-Chancellor of Uremia University research center and all other respectful chairmanships of Shabestar universities and all staff assisted us to perform the study. 


\section{Contribution}

study design: AS, F H

data collection and analysis:

AS,MA,F H

Manuscript writing: AS, M A

\section{Conflict of Interest}

The authors declare that they have no competing interests."

\section{Funding}

The author (s) received no financial support for conducting the research, authorship. and/or publication of this article.

\section{References}

1- Heath GW, Wilkerson G, Oglesby B. Physical activity promotion in a university community using the guide to community preventive services. Acsms Health Fit J2010: 14(5): 7-11

2- Vahedian-Shahroodi M, Elaheh L-m, Esmaily H, Tehrani H, Hamidreza M-H. Prediction of osteoporosis preventive behaviors using the health belief model. Iranian Journal of Health Education \& Promotion2014; 2(3): 199.

3- Bakhtari Aghdam F, Moghaddam MHB, et al. Explaining the role of personal, social and physical environment factors on employed women's physical activity: a structural equation analysis. Global Journal of Health Science2013; 5(4): 189-99.

4- Faghri PD, Omokaro C, Parker C, Nichols E, Gustavesen S, Blozie E. E-technology and pedometer walking program to increase physical activity at work. $J$ Prim Prev 2008:29 (1):73-91.

5- Huang SJ, Hung WC, Sharpe PA, Wai JP. Neighbourhood environment and physical activity among urban and rural schoolchildren in Taiwan. Health Place2010; 16(3): 470-6. 6- Esmaeeli R, Hosseini M, Yaghmaei F. The survey of physical activities in women lectures of university: Development, validation and use of 'Time Diary of Adult Physical Activity'. Journal of Health Promotion Management2012; 1(1): 26-33.

7- Shibata A, Oka K, Harada K, Nakamura Y, Muraoka I. Psychological, social, and environmental. Factors to meeting physical activity recommendations among Japanese adults. Int J Behav Nutr Phys Act2009; 6: 60.

8-Glanz K, Rimer B. Health behavior and health education theory, research, and practice. 4 ed. San Francisco, CA: Jossey-Bass; 2008.

9- Stokol D. Translating social ecological theory into guidelines for community health Promotion. Am J Health Promot1996; 10(4): 282-98.
10- McNeill HL, Kreuterb MW, Subramanian SV. Social environment and physical activity: a review of concepts and evidence. Soc Sci Med2006; 63(4): 1011-22.

11- Elder JP, Leslie L, Sallis JF, et al. A description of the social-ecological framework used in the trial of activity for adolescent girls (TAAg). Health Educ Res2007; 22(2): 155-65.

12- Pan SY, Cameron C, Des Meules M, Morrison H, Craig CL, Jiang X. Individual, social, environmental, and physical environmental correlates with physical activity among Canadians: a cross - sectional study. BMC Public Health2009; 9: 21.

13- Brown WJ, Gilson ND, McKenna J, Puig Ribera A. The international university walking project: a comparison of step counts and sitting times at different sites. Med Sci Sports Exerc2007; 39: s327.

14- Vasheghani-Farahani1 A, Tahmasbi M, Asheri H, Ashraf H, Nedjat S, Kordi R. The Persian, last 7-day, long form of the international physical activity questionnaire: translation and validation study. Asian $J$ Sports Med2011; 2(2): 106-16.

15- Brownson RC, Hagood L, Lovegreen SL, et al. A multilevel ecological approach to promoting walking in rural communities. Prev Med2005; 41(5-6): 837-42.

16- Eyler AA, Matson-Koffman D, Vest JR, et al. Environmental, policy, and cultural factors related to physical activity in a diverse sample of women: the women's cardiovascular health network project-summary and discussion. Women and Health2002; 36(2): 123-34.

17- Nies MA, Vollman M, Cook T. Facilitators, barriers, and strategies for exercise in the Community. Public Health Nurs 1998; 15(4): 263-72.

18- Tudor-Locke C, Lutes L. Why do pedometers work? A reflection upon the factors related to successfully increasing physical activity. Sports Med2009; 39(12): 981-93.

19- Ogilvie D, Bull F, Powell J, et al. An applied ecological framework for evaluating infrastructure to promote walking and cycling: the iconnect study. Am J Public Health201; 101(3): 473-81.

20- Moulton NS. The ecological influences of community trail use and physical activity among female trail users. Utah state: Logan; 2009.

21- Nikpoor S, Haji Kazemi EA, Haghani H. Study of the kind and time of occupational and leisure physical activities employed women in faculties of Iran University of medical sciences. The Razi Journal of Medical Sciences (RJMS)2005; 12(46): 381-92.

22- Bolívar J, Daponte A, Rodríguez M, Sánchez JJ. The influence of individual, social and physical environment factors on physical activity in the adult population in andalusia, Spain. Int J Environ Res Public Health2010: 7(1): 60-77. 
23- Colley RC, Garriguet D, Janssen I, Craig CL, Clarke J, Tremblay MS. Physical activity of Canadian adults: accelerometer results from the 2007 to 2009 Canadian Health measures survey. Health Rep2011; 22(1): 7-14.

24- Fleury J, Lee SM. The social ecological model and physical activity in African American women. Am J Community Psychol 2006; 37(1-2):129-40.

25- Young DR, Stewart KJ. A church-based physical activity intervention for African American women. Fam Community Health2006; 29(2): 103-17.

26- DeCocker KA, DeBourdeaudhuij IM, Cardon GM. The effect of a multi-strategy workplace physical activity intervention promoting pedometer use and step count increase. Health Educ Res2010; 25(4): 608-19.

27- Ishii K, Shibata A, Oka K. Environmental, psychological, and social influences on physical activity among Japanese adults: structural equation modeling analysis. Int J Behav Nutr Phys Act2010; 7: 61.

28- Bandura A. Self-efficacy: The exercise of control. New york: Freeman Co; 1997.

29- Sechrist KR, Walker SN, Pender NJ. Development and psychometric evaluation of the exercise Benefits/ Barriers scale. Res Nurs Health1987; 10(6): 357-65.

30- Sallis JF, Grossman RM, Pinski RB, Patterson TL, Nader PR. The development of scales to measure social support for diet and exercise behaviors. Prev Med1987; 16(6): 825-36.

31- Cleland V, Ball K, Humea C, Timperio A, King AC, Crawford D. Individual, social and environmental correlates of physical activity among women living in socioeconomically disadvantaged neighbourhoods. Soc Sci Med2010; 70(12): 2011-8.

32- Motefaker M, Sadrbafghi SM, Rafiee M, et al. Suic epidemiology of physical activity: a population based study in Yazd cityide attempt and its relation to stressors and supportive systems: a study in Karaj city. Tehran University Medical Journal2007; 65(4): 77-81.

33-Craig C, Marshall A, Sjostrom M, et al. International physical activity questionnaire: 12-country reliability and validity. Med Sci Sports Exerc2003; 35(8): 1381-95. 34- Nazem F, Jalili M. The relation between step count with antropometric risk factors of heart diseas among Hamadanian men. Journal of Hamadan University of Medical Sciences2012; 19(3): 49-56.

35- Jalilian M, Darabi M, Sharifirad Gh, Kakaei H. Interventional program based on trans-theoretical model to promote regular physical activity in office workers. Health-System Research2013; 9(2): 188-19.

36- Solhi M, Zinat Motlagh F, Karimzade Shirazi $\mathrm{K}$, et al. Designing and implementing educational program to promote physical activity among students: an application the theory of planned behavior. Ofogh-eDanesh2012; 1(55): 45-52.

37- Haines DJ, Davis L, Rancour P, Robinson M, NeelWilson T, Wanger S. A pilot intervention to promote walking and wellness and to improve the health of college faculty and staff. J Am Coll Health2007; 55(4): 219-25

38- Lubans DR, Morgan PJ. Social, psychological and behavioural correlates of pedometer Step counts in a sample of Australian adolescents. J Sci Med Sport2009; 12(1): 141-7.

39- Puig-Ribera A, McKenna J, Gilson N, Brown WJ. Change in work day step counts, wellbeing and job performance in Catalan university employees: a randomised controlled trial. Promot Educ2008; 15(4):11-6.

40- Roberts G, Seldon G, Parks K. Human resource management: u.s. small bisiness administration. University of Georgia Athens; 2004.

\footnotetext{
Copyright(C) 2016 ASP Ins. This open-access article is published under the terms of the Creative Commons Attribution-NonCommercial 4.0 International License which permits Share (copy and redistribute the material in any medium or format) and Adapt (remix, transform, and build upon the material) under the Attribution-NonCommercial terms.
} 